\title{
La responsabilidad social empresarial: conciencia, solidaridad y eficiencia
}

\author{
VÍCTOR ASPÍLLAGA ALAYZA*
}

Dichosos los que prestan ayuda, porque esos van a recibir ayuda.

Mt. 5, 1 - 10

SUMARIO. I. CONCEPTO DE RSE.- II. RAZONES DE LA RSE.- III. REGULACIÓN DE LA RSE.- IV. RESUMEN.

La responsabilidad social empresarial (RSE) es un movimiento que promueve en las empresas ${ }^{1}$ la conciencia de velar por la satisfacción y cumplimiento de las expectativas de todos los grupos de interés de la sociedad en los que pueda generar un impacto. Estos grupos de interés, a quienes denominaremos stakeholders - tal como se les conoce en la doctrina estadounidense-, pueden ser grupos de accionistas, inversionistas, empleados y sus familias, la comunidad, los clientes, los proveedores, el medio ambiente y el Estado.

$\mathrm{Al}$ enfocarme en el tema de este ensayo, mi principal pregunta fue la siguiente: ¿cuál es la relación entre la RSE y el Derecho? Mis hipótesis previas a cualquier tipo de investigación se centraron en los siguientes aspectos: (i) el Derecho la regula; (ii) el Derecho la promueve; y (iii) el Derecho la exige. Todas estas afirmaciones encerradas en signos de interrogación.

El filósofo del Derecho británico H.L.A. Hart, partidario de la concepción positivista del Derecho, señalaba que estaba constituido por obligaciones que emanaban de mandatos concretos y de costumbres. En ese sentido, acerca de la RSE y el Derecho, podemos señalar que este último puede llevarnos a que se genere la RSE, y a la vez la RSE puede llevarnos a crear el Derecho que la respalde. Esta, sin embargo, es una afirmación un tanto atrevida. No se puede emitir una norma que diga: «las empresas deberán generar felicidad en todos sus empleados» $\mathrm{O}$ «las empresas deberán recoger la basura que se encuentre en la calle donde se ubique su domicilio».

Conocemos los escenarios que se reflejan cuando una empresa cumple con lo que propone la RSE; sin embargo, icuál es el papel del Derecho

* Es alumno del séptimo ciclo de la especialidad de Derecho en la Pontificia Universidad Católica del Perú.

1 A lo largo de este ensayo, por «empresa» deberá entenderse lo siguiente: «Unidad de organización dedicada a actividades industriales, mercantiles o de prestación de servicios con fines lucrativos». Diccionario de la Lengua Española. Vigésimo Segunda Edición. En <http://buscon.rae.es/drael/ SrvltConsulta?TIPO_BUS=3\&LEMA=empresa>. Fecha de consulta: 11 de octubre de 2009.

TRABAJO GANADOR DEL CONCURSO DE ENSAYOS REALIZADOS ENTRE ALUMNOS DE LA FACULTAD DE DERECHO DE LA PUCP 
a efectos de promover más estos escenarios? El objetivo de este trabajo será determinar cuál es el papel del Derecho para lograr la meta de conseguir que el mercado empresarial peruano se avoque —conjuntamente con su objetivo natural de proveerse de utilidades - a generar bienestar y tomar en cuenta los intereses de todos sus stakeholders.

En ese sentido, voy a empezar explorando el concepto de la RSE; después, analizaré cuáles son las razones de su existencia; finalmente, determinaré si sería viable su regulación y en qué forma.

\section{CONCEPTO DE RSE \\ I.1. Algunos ejemplos}

Existen grandes empresas que tienen como activos las marcas más queridas por la sociedad. Todas son empresas conocidas y damos por sentado que son «buenas». Normalmente, las conocemos por distintas razones: desde ver un letrero en la calle o su logo en la camiseta de nuestro equipo deportivo favorito, o por realizar constantemente promociones que la hacen popular entre los consumidores.

Por ejemplo, iquién no percibe a Coca-Cola como una empresa amigable? La Coca-Cola promueve siete objetivos ulteriores a su objetivo de producir la gaseosa que todos conocemos:

1. devolver al medio ambiente la misma cantidad de agua que consumió en su proceso de producción;

2. promover los «empaques sustentables» (es decir, promueve el reciclaje y educa a la gente en torno al mismo objetivo);

3. ampliar su variedad de productos y presentaciones a efectos de satisfacer a todos los tipos de consumidores;

4. promover la salud y la actividad física al apoyar y auspiciar eventos y clínicas deportivas;

5. apoyar a la comunidad mediante distintos tipos de programas y donaciones;

6. cumplir con las expectativas de sus trabajadores, al ser elegida como uno de los mejores lugares para trabajar; y

7. apoyar el medio ambiente con programas de desde reforestación hasta de reducción de emisiones de $\mathrm{CO} 2$ por parte de sus distribuidores ${ }^{2}$. 
De esta forma, vemos que Coca-Cola, inicialmente parte de la producción y venta de bebidas, realiza una serie de aportes a la sociedad. Esta empresa recicla, auspicia al deporte, a la comunidad, aporta al medio ambiente, etcétera. Las empresas que practican la RSE exceden lo que la sociedad y el Estado esperan de ellas.

La empresa Telefónica del Perú también realiza actividades como las ya señaladas: es decir, excede las expectativas de la gente y muchas veces satisface sus necesidades, al ir más allá del giro ordinario de su negocio. Cuenta con distintos programas de carácter global promovidos por el Grupo Telefónica a través de la Fundación Telefónica, entre estos:

Proniño, cuyo objetivo es contribuir a erradicar el trabajo infantil por medio de la escolarización; Educared, cuyo objetivo es mejorar la educación; Fórum, que atiende a la generación del conocimiento en el entorno de la Sociedad de la Información y su impacto social; el programa Arte, Cultura y Patrimonio Histórico Tecnológico, que promueve el desarrollo artístico usando las nuevas tecnologías; y por último, el programa Voluntarios Telefónica, por medio del cual se busca el fomento y la participación de los empleados del Grupo en diferentes actividades de acción social ${ }^{3}$.

A diferencia del primer ejemplo, esta empresa, además, se ocupa de la educación, del arte y de la cultura, y promueve actividades sociales entre sus empleados.

\subsection{Características de la RSE}

De acuerdo a lo señalado en el punto 1.1, pueden extraerse dos características principales de la RSE: (i) representa una acción de las empresas que va más allá de lo exigido por la ley; y, por lo tanto, (ii) es voluntaria.

Existen discrepancias en torno a las características de la RSE en los países desarrollados y en aquellos en vías de desarrollo. Antonio Vives señala que la RSE, en los países desarrollados, se centra en mitigar, a través de la ella, todo el impacto de la empresa en la sociedad. En los países en vías de desarrollo, ante la debilidad e ineficacia del Estado, la RSE extiende el impacto de manera positiva - no solo lo mitiga, sino que lo favorece- y suplanta en muchos casos la actividad estatal, lo cual tiende posteriormente a beneficiar al Estado, pues muchas veces la empresa asume servicios por naturaleza públicos ${ }^{4}$.

En muchos lugares del mundo, se debate acerca de la naturaleza de la RSE y de sus implicancias en la sociedad. En ese sentido, la Unión Europea difunde un documento denominado el Libro Verde, cuyo objetivo

3 Fundación Telefónica. En <http://www.telefonica.com.pe/fundacion/>. Fecha de consulta: 8 de septiembre de 2009.

4 VIVES, Antonio. "Corporate social responsibility: the role of law and markets and the case of developing countries». Chicago-Kent Law Review, № 199, 2008, Chicago. Base de datos LexisNexis Academics. 
es: «[...] iniciar un amplio debate y recabar opiniones sobre la responsabilidad social de las empresas a nivel nacional, europeo e internacional. La Comisión [Europea] espera que esta iniciativa desemboque en el establecimiento de un nuevo marco para el fomento de la responsabilidad social de las empresas» ${ }^{5}$.

En ese sentido, el mismo Libro Verde define la RSE como la integración voluntaria, por parte de las empresas, de las preocupaciones sociales y medioambientales en sus operaciones comerciales y en sus relaciones con sus interlocutores - es decir, sus stakeholders-. Así, los objetivos de la RSE para las empresas, a la larga, constituyen una inversión en su futuro, a la espera de que el compromiso que han adoptado voluntariamente contribuya a incrementar su rentabilidad ${ }^{6}$.

Este debate, iniciado en Europa, parte simplificando la RSE en dos dimensiones: interna y externa. La dimensión interna envuelve a los trabajadores de la empresa, a los accionistas y al medio ambiente; es decir, se afectan aspectos como: (i) la gestión de recursos humanos; (ii) la salud y seguridad en el lugar de trabajo; (iii) la adaptación al cambio; y (iv) la gestión del impacto ambiental y los recursos naturales.

La dimensión externa envuelve las relaciones de las empresas con socios comerciales y proveedores, consumidores, autoridades públicas y organizaciones no gubernamentales defensoras de los intereses de las comunidades locales y el medio ambiente. De esta forma, se afectan los siguientes aspectos: (i) desarrollo de las comunidades; (ii) asociaciones con otras empresas para ayuda mutua; (iii) aumento de calidad enfocada a la satisfacción al consumidor; (iv) promoción de los derechos humanos; y (v) enfrentamiento a los problemas ecológicos mundiales.

En ese sentido, el Libro Verde nos ayuda a ordenar el debate, pues aporta distintas ideas acerca de cómo las empresas pueden practicar la RSE y contribuir a ayudarse tanto en su dimensión interna como externa. De esta manera, se duplica el efecto de no solo ayudarse a sí misma — pues, tal como ya lo señalamos, un beneficio de la RSE es incrementar las utilidades de la empresa-, sino de cumplir un papel solidario de ayuda a la sociedad.

\section{RAZONES DE LA RSE}

De acuerdo a lo señalado en el capítulo precedente, podemos afirmar que las razones que sustentan la existencia de RSE equivalen a los beneficios que se pueden generar para con la comunidad y la propia empresa. Estamos ante un acto de inversión por parte de la empresa: ella coloca

5 Libro Verde. «Introducción», numeral 19. En <http://eur-lex.europa.eu/LexUriServ/LexUriServ.do?uri =CELEX:52001DC0366:ES:HTML>. Fecha de consulta: 12 de septiembre de 2009.

6 Libro Verde. Óp. cit., numerales 1 y 20. 
sus recursos excedentes en el mercado, a la espera de generar una renta aun mayor.

Las empresas, al obtener recursos o utilidades por sus actividades, suelen optar por: (i) repartir estos recursos en forma de dividendos a todos sus accionistas; o (ii) reinvertirlos en la empresa por distintos motivos: por ejemplo, comprar mejor maquinaria para aumentar la producción y generar economías de escala, o aumentar sueldos a sus empleados para atraer gente más capacitada, que pueda darle mayor valor a la empresa - lo cual, a su vez, es considerado un acto de RSE, como veremos más adelante-

Una tercera opción, que bien puede ser considerada una reinversión en la propia empresa, es la de invertir en actos de RSE. La diferencia está en que la inversión en estos actos, además de favorecer a la propia empresa, favorece también a terceros. Cabe distinguir que pueden existir actos de reinversión de una empresa que favorezcan a terceros pero que no sean calificados como actos de RSE: por ejemplo, cualquier acto de reinversión que genere externalidades positivas?

Un caso de estos puede ser, por ejemplo, aquel en que una empresa decide construir una planta hidroeléctrica en un río situado en un lugar recóndito del país, donde se encuentra un pueblo con escasos recursos. El impacto positivo inmediato será el aumento del consumo en el pueblo, dado que ahora tiene como público objetivo a todos los trabajadores de la empresa recién establecida en el lugar, los cuales acudirán al pueblo en su tiempo libre como consumidores de cualquier bien o servicio que pueda proveer dicho pueblo. Este tendrá un mercado monopólico y podrá desarrollarse. Otro efecto podría ser incluso la contratación de personas en ese pueblo para cubrir puestos de trabajo en la empresa - nótese que el pueblo sería prácticamente una fuente monopólica de mano de obra para la empresa-.

El ejemplo señalado se distingue de un acto de RSE por la intención de la empresa: no fue beneficiar al pueblo, sino generar una externalidad positiva. Un acto de RSE hubiera consistido, como ya lo señalamos líneas arriba, en llevar a cabo una acción voluntaria que exceda los requerimientos legales y que, además, sea en favor de terceros. Ejemplo de ello sería contratar a los pobladores a efectos de construir una escuela para proveer de educación, no solo a los mismos pobladores, sino a los hijos de los trabajadores de la hidroeléctrica. Así, los trabajadores tendrían la ventaja de trasladarse con sus familias hasta el lugar donde se establece la planta, sin tener que alejarse de ellas para trabajar.

TRABAJO GANADOR DEL CONCURSO DE ENSAYOS REALIZADOS ENTRE ALUMNOS DE LA FACULTAD DE DERECHO DE LA PUCP 
Existen distintas razones y, por ende, beneficios que se pueden obtener practicando RSE. Entre estos se encuentran los siguientes, clasificados por Solano:

1. disminuye los costos por paralización de operaciones o seguridad, al reducir la posibilidad de conflictos con la población;

2. mejora la productividad, al contar con trabajadores motivados o con mejores condiciones de salud, lo cual contribuye a incrementar su fidelidad con la empresa;

3. mejora el ambiente interno y la seguridad de los trabajadores, al considerar sus necesidades;

4. mejora el ambiente externo, al identificar y mitigar los impactos que sus actividades pueden generar en el entorno; $y$

5. proyecta una imagen de responsabilidad en la empresa.

Las razones que describe Solano tienen todas en común lo siguiente: a diferencia de actos comunes de inversión, que proveen beneficios exclusivamente a los accionistas de la empresa, estos generan beneficios también a terceros y al Estado.

Estos actos, que generan beneficios a las empresas, resultan deseados por todos los stakeholders. Líneas arriba señalamos que, de acuerdo con H.L.A. Hart, el Derecho estaba constituido por obligaciones que emanaban de mandatos concretos y de costumbres. Actualmente, la sociedad experimenta un fenómeno importante: el Derecho, dadas las costumbres voluntarias de algunas empresas, les está exigiendo este tipo de acciones.

¿Qué sucede? La respuesta es simple. Muchas empresas multinacionales se han desarrollado a tal punto que sus ventas superan ampliamente incluso el producto bruto interno (PBI) del Perú. Así por ejemplo, las ventas anuales de Toyota Motor son de US\$263,42 billones de dólares, en tanto que el PBI del Perú para 2008 fue de US $\$ 127,70$ billones de dólares ${ }^{9}$. Al respecto, Levine ${ }^{10}$ señala que, en muchos casos, fueron las empresas quienes voluntariamente iniciaron programas de RSE. Sin

8 SOLANO, David. «Responsabilidad social corporativa: qué se hace y qué debe hacerse», p. 5. En <http://www.esan.edu.pe/paginas/publicaciones/cuadernos/18_19/Cuad18-19Solano.pdf.>. Fecha de consulta: 15 de septiembre de 2009 .

9 Las cifras fueron extraídas de las siguientes fuentes: “Las empresas más grandes del mundo", p. 3, en <http://pe.invertia.com/herramientas/galerias/galeria.aspx?galeria=457> (fecha de consulta: 21 de septiembre de 2009); y Ministerio de Economía y Finanzas. Marco Macroeconómico Multianual 2009-2011, agosto de 2008, p. 12, en <http://www.mef.gob.pe/ESPEC/MMM2009_2011/ MMM_2009_2011_Revisado.pdf> (fecha de consulta: 24 de septiembre de 2009). Vale resaltar que Toyota Motor duplica el producto bruto interno de nuestro país, por lo que se encontraría en una mejor posición para asumir proyectos que podrían ser más eficientes para ella misma que para el Estado peruano, pero que normalmente suelen ser «tarea del Estado».

10 LEVINE, Michael, . «Legislating corporate social responsibility». Comentario en el blog GreenBiz, abril de 2007. En <http://www.greenbiz.com/blog/2007/04/23/legislating-corporate-social-responsibility>. Fecha de consulta: 24 de septiembre de 2009. 
embargo, dado su impacto, el Estado dictaba lineamientos para llevar a cabo estos programas de la manera más eficiente. En el Perú, también se hizo costumbre. Por ello, el Estado, partiendo de lineamientos, pasa a establecer límites y, como señala Levine, eventualmente terminará por establecer obligaciones.

Esta idea, como hemos reflejado, y dada la mayor capacidad económica de algunas empresas, no es del todo descabellada. El Congreso de los Estados Unidos argumenta que las empresas que voluntariamente realizan programas de RSE fuera de los Estados Unidos no respetan, en los países en que operan, los estándares requeridos por su legislación. Dicho de otro modo, van más allá de la legislación de los países en los que operan (RSE), pero incumplen los requerimientos de su legislación nacional —en este caso, de Estados Unidos-.

Así, el ejemplo en que se basa Levine, a propósito de Estados Unidos, parte de los requerimientos que hizo su Congreso a los países con quienes recientemente suscribieron tratados de libre comercio, nada menos que Perú, Colombia, Panamá, Malasia y Corea ${ }^{11}$. En estos tratados, se exigió a las empresas cumplir con una serie de estándares totalmente ajenos a las legislaciones de los países donde operaban. Se exigió que las empresas cumplieran los mismos requerimientos legales tanto en los Estados Unidos como en su Estado contraparte en el tratado. Resultaba injusto para los Estados Unidos que las empresas operen a menores costos en su país contraparte, por más de que lo hicieran paralelamente a la ejecución de programas de RSE. Justos podrían pagar por pecadores, con la amenaza de ver fiscalizados sus programas de RSE.

\section{REGULACIÓN DE LA RSE}

El asunto a tratar en este punto es la determinación de si el Derecho es un medio de ayuda para la promoción de la RSE y, de serlo, en qué medida. Asimismo, se busca determinar qué tipo de normas deben estar presentes en esta regulación, así como cuál sería su nivel de exigibilidad.

A efectos de ser mejor comprendido, ilustraré este capítulo con un ejemplo inspirado en una interesante clase de Análisis Económico del Derecho, dictada por el doctor Alfredo Bullard Gonzales.

Existe una conocida serie en la televisión llamada Dr. House. Esta serie narra la historia de un excéntrico médico - a quien en adelante llamaremos House-, encargado del departamento de diagnóstico de un hospital. En cada capítulo, su función consiste en tomar los casos cuya solución es desconocida para los demás médicos. Al ocurrir ese supuesto, se envía el caso del paciente a House, cuyas funciones son descubrir cuál es el mal que afecta al paciente y, de acuerdo a ello, aplicar

TRABAJO GANADOR DEL CON-

CURSO DE ENSAYOS REALIZADOS ENTRE ALUMNOS DE LA FACULTAD DE DERECHO DE LA PUCP 
el tratamiento médico correspondiente. Sin embargo, hasta que no logra determinar exactamente cuál es el problema, no se puede aplicar solución alguna: un tratamiento equivocado puede generar más daños.

Una vez llegado el caso, House se sienta en una sala con su equipo de médicos, donde todos desarrollan una «lluvia de ideas» sobre la base de los síntomas que presente el paciente. Ellos trabajan con supuestos. Por ejemplo, ante los síntomas X, Y, y Z, deben aplicar la medicina N. Pero si $\mathrm{X}$ no fuese propiamente un síntoma, no deben aplicar N, sino $\mathrm{M}$.

Un caso de House no es muy diferente a la tarea de un legislador o a la de un congresista de la república ${ }^{12}$ : los «síntomas» que estos deben analizar son las conductas de la sociedad y el «tratamiento» será la norma bajo su composición tradicional de «supuesto y consecuencia». Así, si el tratamiento (norma) aplicado al paciente (sociedad) es incorrecto, los síntomas continuarán y probablemente se generen, en consecuencia, nuevos males.

Digamos que el Congreso detecta una conducta indeseable en la sociedad, como el robo. El robo es el síntoma. La norma que pretenda erradicarlo deberá contener el supuesto del robo y una consecuencia (el tratamiento) en caso de que este se configure. Así lo señala el artículo 188 del Código Penal: «El que se apodera ilegítimamente de un bien mueble total o parcialmente ajeno [...]», como consecuencia, «[...] será reprimido con pena privativa de libertad no menor de tres ni mayor de ocho años». Con este «tratamiento» se curan estos «síntomas» de la sociedad y a la vez se generan otros, como el respeto a la propiedad privada.

Entonces, la tarea de un legislador, en caso de que se quiera generar un síntoma como la RSE, será similar a la de House: deberá determinar que «síntomas» van a ser generados por un «tratamiento» determinado. Si el legislador quiere generar el síntoma de que las empresas practiquen la RSE, deberá crear una norma que genere tal síntoma, y así regularía un supuesto y una consecuencia que permitan la generación de la RSE como resultado.

\section{III.1 Diseño de la legislación}

Entre las herramientas que puede emplear el legislador para averiguar si los resultados que van a generar las normas en la sociedad son los deseados, se encuentra el Análisis Económico del Derecho. El Análisis Económico del Derecho (AED), a decir de Richard Posner:

[...] trata de explicar y predecir el comportamiento de los participantes en el sistema legal, e inclusive la estructura doctrinaria, procesal e institucional del sistema. Pero además, trata de mejorar el Derecho al señalar aquellos aspectos en que las leyes existentes o los proyectos de 
leyes generan consecuencias no deseadas o no propuestas y a formular reformas prácticas ${ }^{13}$.

En ese mismo sentido se expresa Bullard cuando señala, con respecto al funcionamiento del AED, que «[...] no es otra cosa que tratar de poner al alcance del abogado herramientas para poder diseñar mejor su 'operación' mediante la predicción de su resultado y para poder, luego de 'operado el paciente', medir si tuvo o no éxito» ${ }^{14}$.

Por lo tanto, en el presente caso, el AED representará la perspectiva a través de la cual intentará obtener nociones que orienten cómo debe estar enfocada una legislación que persiga promover la RSE en nuestro país. Como hemos señalado, nos referiremos al AED en su forma más común, y trataremos de explicar la racionalidad económica de las regulaciones y de las prácticas de los agentes del mercado.

En ese sentido, los medios más utilizados por los economistas para predecir resultados están basados en la simplificación de la realidad, al asumir distintos escenarios que cumplan este objetivo. Así, tal como lo hace House mediante modelos de predicción como los síntomas, se va delineando cuál es el problema que se va a presentar y cuál es la vía para solucionarlo.

No obstante, deben tenerse en cuenta ciertos supuestos previos básicos de las hipótesis económicas: (i) toda preferencia tiene un valor determinado en una unidad de referencia - costo contra beneficio-, por ejemplo el dinero; (ii) todo agente en el mercado siempre buscará la maximización de su utilidad — entendiéndola sobre la línea de su preferencia y siempre aplicando la unidad de valor de referencia ya señalada para reflejar su intensidad - ; (iii) las preferencias de los agentes se mantienen estables; y (iv) la situación de máxima utilidad será la de eficiencia para el agente ${ }^{15}$.

\section{III.2. A modo de ejemplo: dimensión externa}

Establezcamos un escenario ejemplar mediante el cual una empresa debería optar por una práctica de RSE. Supongamos que la empresa

13 PosneR, Richard. «El movimiento del Análisis Económico del Derecho: desde Bentham hasta Becker». Themis, № 44, p. 47, 2002, Lima.

14 Bullard Gonzales, Alfredo. Derecho y economía. Segunda edición. Lima: Palestra, 2006, p. 73.

15 De acuerdo con Juan José Haro: «La eficiencia social se define normalmente en el Análisis Económico del Derecho por referencia al criterio de Pareto. De acuerdo con este criterio, una decisión (por ejemplo, incurrir en costos de transacción) será eficiente si genera beneficios por lo menos para uno de los miembros de la sociedad y no produce perjuicios para ninguno. El criterio de Pareto resulta insuficiente para explicar las razones por las que ciertas decisiones que perjudican a algunos individuos son sin embargo deseables desde un punto de vista social. La utilización de vehículos motorizados, por ejemplo, beneficia a aquellos que los usan pero contamina el ambiente y genera perjuicios que deben ser soportados incluso por aquellos que no tienen un vehículo motorizado o prefieren desplazarse por otros medios. Este tipo de decisiones solo puede considerarse eficiente si se adopta el criterio de Kaldor-Hicks, un criterio un poco más flexible de 'eficiencia', de conformidad con el cual una decisión es eficiente si los beneficios agregados de esta superan a los perjuicios agregados». HARO SEIJAS, Juan José. «¿Podría usted 'no hacer' negocios conmigo? Sobre la responsabilidad precontractual y la buena fe». Advocatus, № 7, p. 130, 2002, Lima.

TRABAJO GANADOR DEL CONCURSO DE ENSAYOS REALIZADOS ENTRE ALUMNOS DE LA FACULTAD DE DERECHO DE LA PUCP 
A, productora y comercializadora de neumáticos, quiere hacerse más conocida en el mercado para aumentar las preferencias por parte de los consumidores. La primera idea que a cualquier individuo se le viene a la mente es que la empresa desarrolle o contrate publicidad. Sin embargo, esta no es la única opción. Supongamos que la empresa A tiene dos alternativas:

1. Alternativa publicitaria. Contrata un anuncio en la televisión. Este le costaría cien soles y obtendría beneficios por trescientos soles.

2. Alternativa de RSE. Apoya la selección femenina de vóley del país donde se encuentra domiciliada — comprando ropa deportiva, pagando algún viaje del equipo o premiando a las jugadores- a cambio de que ellas lleven el logo de la empresa en sus camisetas. Esto le costaría doscientos soles y obtendría beneficios por trescientos.

Ante ello, el anuncio en la televisión resulta en apariencia más eficiente, esto debido a distintos factores: permite brindar más información sobre el producto y llegar a muchos televidentes, por ejemplo. Entonces, iqué incentivos puede acarrear la normativa para que una empresa opte, en un caso como este, por la opción de RSE? Analicemos las verdaderas opciones de la empresa - escondidas detrás de algunos costos de transacción-.

En el ejemplo contemplado, la empresa A gana cien soles más por realizar su publicidad a través de la televisión; sin embargo, icuales serían los beneficios para la sociedad si la empresa invirtiera en el equipo de vóley? Habría muchos más. Una selección nacional de vóley con apoyo económico posee mayores posibilidades de ganar que otra sin apoyo. $\mathrm{Si}$ gana, el equipo será conocido y más personas estarán en contacto con la marca de la empresa A. Bien, en realidad no solo estarán en contacto con ella sino que la preferirán, pues es gracias al apoyo de la marca que la selección logró superarse.

Otros beneficios relacionados son que el público se sentirá orgulloso del equipo, el éxito deportivo se difundirá, las familias incentivarán a sus hijos a practicar deporte y estos, a su vez, recibirán una formación disciplinada gracias al deporte y crecerán alejados de drogas y malos hábitos. Se crea así una positiva reacción en cadena que, a la larga, se acerca al Óptimo de Pareto en mucho más medida que los inicialmente eficientes cien soles con los que medimos la primera ganancia con respecto de la segunda ${ }^{16}$. 
Entonces, la alternativa en que la empresa A contrata un anuncio en televisión y gana doscientos soles resulta eficiente, pero otra situación puede ser potencialmente mejor. ¿Qué sucede? Pues la empresa A no tiene la certeza de que el equipo de vóley realmente obtenga un triunfo y genere la positiva reacción en cadena que señalamos. Sin esta información, es poco probable que alguien inicialmente decida sacrificar cien soles solo ante la probabilidad de generar, digamos, quinientos soles, cuando bien puede ganar doscientos de forma segura. ¿Qué puede hacerse al respecto?

\section{III.2.1 Incentivos tributarios}

El Estado puede hacer mucho: por ejemplo, otorgar incentivos tributarios a la reinversión social de las utilidades de las empresas. Así, una empresa como A aminoraría el costo de la probabilidad de ganar quinientos soles, de tal manera que esta inversión le resultase más atractiva que la publicitaria.

Como ya lo señalamos, las empresas obtienen utilidades que bien pueden ser entregadas a los accionistas en forma de dividendos, o bien pueden ser reinvertidas en la misma sociedad como forma de aumentar el valor de la empresa, o bien pueden ser destinadas a un tercer rubro: la inversión social (RSE). Esta inversión puede ser incentivada de manera eficiente con una menor imposición tributaria a las utilidades destinadas a ella, pues, al final, el beneficio generado por la RSE será no solo para el equipo de vóley, sino también para la sociedad y para el Estado.

El Estado, pues, suele controlar factores económicos importantes mediante la carga tributaria impuesta a distintos destinos asignados a las utilidades generadas por la empresa. Por ejemplo, si grava con un 5\% la utilidad destinada a la reinversión en la propia empresa y grava con $10 \%$ la utilidad destinada al reparto de dividendos, generará que las empresas reinviertan más y crezcan más, lo cual probablemente generaría mayores utilidades en el siguiente ejercicio. Con la figura opuesta, $5 \%$ al reparto de dividendos y $10 \%$ a la reinversión, el fisco ocasionará que más personas deseen invertir en acciones y, en consecuencia, se registrarán más posibilidades de financiamiento para las empresas. Esta medida para promover la entrega de dividendos podría incluso generar un aumento en el consumo, dado que los accionistas reciben dinero producto de los dividendos $-\mathrm{y}$, viéndolo desde otra perspectiva, podría hasta generar inflación como consecuencia del aumento del consumo-.

Una carga tributaria más leve para la reinversión social —con utilidades destinadas a acciones de RSE - aumentará los niveles de RSE. Sin embargo, pueden generarse algunos problemas de agencia ${ }^{17}$, dado que

TRABAJO GANADOR DEL CONCURSO DE ENSAYOS REALIZADOS ENTRE ALUMNOS DE LA FACULTAD DE DERECHO DE LA PUCP 
el Estado previamente debe establecer qué acciones serían consideradas de «inversión social» y, por lo tanto, cuáles serán beneficiadas con este beneficio tributario. Además, deben generarse incentivos dentro de la empresa que destine efectivamente ese dinero a la inversión social, mas no de aquellas que se beneficien con la exoneración y luego apliquen sus recursos a otro tipo de inversiones. Debe evaluarse entonces si este «costo de agencia» (de supervisión) no es mayor al beneficio efectivamente obtenido.

\section{III.2.2 Publicidad de la RSE}

En los Estados Unidos, se fomenta que las empresas inviertan en RSE a través de la promoción. Como ya señalamos, las personas prefieren las empresas que practican la RSE y todas las empresas necesitan financiamiento. Muchas acuden al mercado de valores, donde, como sujetos deficitarios — con poca liquidez-, ofrecen valores a sujetos superavitarios — con excedentes líquidos — que buscan invertir y obtener rentabilidad con el dinero extra que obtienen.

Los sujetos deficitarios, siempre que cumplan con los requisitos exigidos por la normativa vigente para emitir valores en el mercado de valores, emiten capital a efectos de ser suscrito por terceros mediante una oferta pública. Una vez suscritos, estos valores representativos del capital social de las empresas se transan diariamente en el mercado secundario del mercado de valores. Así, estos valores representativos del capital social, o emisiones de deuda de distintas empresas, cambian de manos cada día gracias a este mercado secundario. Uno de los atractivos del mercado de valores es la liquidez de los valores mobiliarios: los inversionistas los adquieren, generan cierta rentabilidad durante un período determinado y, cuando necesitan su dinero nuevamente, los venden.

Los valores se transan todos los días en un mecanismo centralizado de negociación. En el Perú, estas transacciones se realizan en la rueda de bolsa de la Bolsa de Valores de Lima (BVL). Esta maneja distintos índices para medir su rentabilidad a efectos de que los inversionistas perciban cuál es la rentabilidad que ofrece en determinado momento ${ }^{18}$.

Existen índices, como el Índice General de la BVL, que reflejan la tendencia promedio de las cotizaciones de las principales acciones inscritas en bolsa en función de una cartera seleccionada, que actualmente representa a las 38 acciones más negociadas del mercado. Su cálculo considera las variaciones de precios y los dividendos o acciones liberadas repartidas, así como la suscripción de acciones. Otros índices, como el Índice Selectivo de la BVL, envuelven una cartera de

agente directamente, este podría no tomar las precauciones adecuadas si no es incentivado de la manera correcta. POSNER, Eric. «Coloquio de Análisis Costo-Beneficio: análisis del costo-beneficio como una solución al problema principal-agente». Themis, № 44, p. 118, 2002, Lima.

18 El Mercado Bursátil al Día. Índices de Mercado. En <http://www.bvl.com.pe/indicesmercado.html>. Fecha de consulta: 23 de septiembre de 2009. 
acciones seleccionadas de acuerdo a la mayor liquidez de las empresas. También se cuenta el Índice Nacional de Capitalización, que mide las acciones de acuerdo al tamaño de su mercado, es decir, por el mayor porcentaje de su capital negociado habitualmente en la BVL ${ }^{19}$.

Los índices anteriormente señalados fueron determinados de acuerdo a criterios netamente económicos. Sin embargo, existen otros índices, como el Índice de Buen Gobierno Corporativo ${ }^{20}$, que tienen como objeto reflejar el comportamiento de los precios de las acciones de aquellas empresas listadas que adoptan buenas prácticas de gobierno corporativo. Este se basa en un criterio no económico para diferenciar a las empresas que llevan un buen gobierno corporativo ${ }^{21}$ de las que no, para que los inversionistas que decidan adquirir sus valores tengan la certeza de que, por ejemplo, estas empresas respetan los derechos de los accionistas, de que los tratan de manera equitativa, de que son transparentes, etcétera ${ }^{22}$.

Sobre esa misma línea, en Estados Unidos la firma administradora de fondos de inversión KLD Research \& Analytics Inc. (KLD) se especializa en administrar una cartera de valores de empresas que practican la $\mathrm{RSE}^{23}$. Administra fondos de empresas que son conscientes y que intervienen en favor de distintas causas, como aquellas que buscan resolver el calentamiento global, ciertos problemas sociales o hasta el propio buen gobierno corporativo.

Esta firma, además, tuvo la iniciativa de crear un índice compuesto por las cien empresas que promueven mecanismos que buscan evitar y/o prevenir los potenciales daños ocasionados por el ya inminente calentamiento global ${ }^{24}$. Así, el primero de julio de 2005 se creó el KLD Global Climate 100 Index, cuyas empresas integrantes realizan distintas actividades en favor de la causa señalada: comercialización de energías renovables — como la solar y la eólica—, generación de combustibles a base de gas natural e hidrógeno - tanto en niveles de investigación como producción-e innovaciones o aplicaciones de nuevas tecnologías que ayudan a reducir las emisiones de gases contaminantes.

Puede verse cómo KLD, una empresa cuya función es administrar una cartera de valores que genere la mayor rentabilidad posible a sus inversionistas, se preocupa a su vez de premiar a las empresas que practican

19 Ibíd.

20 lbíd.

21 Cabe señalar que las prácticas de buen gobierno corporativo son consideras acciones de RSE, dado que voluntariamente cumplen los requisitos de velar por los intereses de los stakeholders -en este caso, de los accionistas - y a que incluso superan lo exigido por la Ley.

22 Comisión Nacional Supervisora de Empresas y Valores y Otros. «Principios de buen gobierno corporativo para las sociedades peruanas», julio de 2002. En <http://www.confiep.org.pe/facipub/ upload/publicaciones/1/137/2bpublicacionprincipiosdebuengobierno.pdf>. Fecha de consulta: 24 de septiembre de 2009.

23 KLD Research \& Analytics, Inc. En <http://www.kld.com/>. Fecha de consulta: 28 de septiembre de 2009.

24 BAUE, William. «New KLD Index Benchmarks 100 Global Companies Proactively Addressing Climate Change», julio de 2006. En <http://www.socialfunds.com/news/article.cgi/1748.html>. Fecha de consulta: 28 de septiembre de 2009.

TRABAJO GANADOR DEL CONCURSO DE ENSAYOS REALIZADOS ENTRE ALUMNOS DE LA FACULTAD DE DERECHO DE LA PUCP 
la RSE. Hacen públicas sus iniciativas y permiten que personas con voluntad de destinar parte de sus excedentes a la inversión social puedan hacerlo. De esta forma, las empresas que practican RSE obtienen el financiamiento que necesitan debido a sus políticas de RSE. Existen inversionistas que prefieren sacrificar un punto porcentual de la rentabilidad de su cartera a cambio de aportar a la sociedad algo más que su inversión específica.

El razonamiento de este tipo de inversionistas, cuya satisfacción es mayor a la de aumentar su rentabilidad neta, favorece al Estado y a toda la sociedad dado que generan resultados más cercanos al Óptimo de Pareto. Repasemos por qué ocurre esto.

Un inversionista $\mathrm{X}$ tiene cien soles de excedente, dispuestos a ser invertidos en el mercado de valores. Sus opciones varían y, al ser X un inversionista no especializado, opta por canalizar su inversión a través de un fondo de inversión. La empresa administradora de fondos de inversión — similar a KLD — ofrece una variada cantidad de opciones en las cuales invertir, diferenciadas en la potencial rentabilidad y en el rubro de inversión: habrá de alto, mediano y de bajo riesgo, y se podrá invertir en valores de empresas inmobiliarias, mineras, industriales, etcétera. Un rubro distinto es aquel que propone KLD: empresas que tengan en común la práctica de la RSE, llamado Fondo RSE.

Entonces, si X invierte en el fondo de empresas mineras (Fondo Minero) obtendrá una rentabilidad de $10 \%$ de lo invertido, mientras que si lo hace en el Fondo RSE obtendrá una rentabilidad de 9\%. La decisión más eficiente para X será invertir en el Fondo Minero. Sin embargo, este contiene valores de empresas que no practican la RSE y que incluso generan externalidades negativas. La rentabilidad para el inversionista será de 10\%. Mientras tanto, la sociedad, destinataria de sus fondos, recibirá tan solo diez soles provenientes de la recaudación tributaria después de descontar los daños ambientales que irresponsablemente la empresa genera (tomemos en cuenta que la empresa en la que se invierte está, a su vez, invirtiendo en el país y que obtendrá utilidades que serán grabadas con tributos).

Por otro lado, si X decide invertir en el Fondo RSE, su rentabilidad como inversionista será de $9 \%$ de lo invertido en principio - más adelante se explicará por qué «en principio»—, mientras que para el Estado será de quinientos soles, obtenidos a partir de la recaudación tributaria y de la inversión social (RSE) realizada por las empresas constituyentes del fondo.

Ocurre que una de las empresas que conforman el Fondo RSE es una minera que no contamina y que construyó una carretera desde el sitio donde se ubica su principal mina - para transportar los minerales extraídos- hasta el puerto de la ciudad más cercana, y que con una pequeña desviación logra pasar por un pueblo cercano a la mina que antes no contaba con dicha carretera y que, por ende, se hallaba 
incomunicado. Así, esta carretera, con una sobreinversión poco relevante por parte de la minera, permitió integrar el mencionado pueblo al mercado, y ello generó bienestar y recursos para todos sus habitantes. El Estado obtuvo no solo el beneficio de la carretera, sino el desarrollo de un pueblo, ahora formal, que logra insertarse en el mercado, competir, formalizarse, autosostenerse, reinvertir, preparar a su gente e incluso aumentar la base tributaria en favor del Estado.

El inversionista $\mathrm{X}$ gana en principio un punto porcentual menos, pero el país inserta a todo un pueblo en la economía, y se genera bienestar en la sociedad y una positiva reacción en cadena, similar a la señalada en el caso del equipo de vóley. En tal sentido, ipor qué decimos que el inversionista gana «en principio» 9\%? Pues porque la inversión en una empresa que genera externalidades negativas promueve, a su vez, que más empresas las generen a efectos de aumentar su rentabilidad y obtener el financiamiento necesitado. En el futuro, las externalidades negativas generadas por las empresas aumentarían hasta llegar a afectar al propio inversionista y serían al final de cargo del Estado, y por tanto de los contribuyentes, entre estos el inversionista y la empresa.

\section{III.3. A modo de ejemplo: dimensión interna}

La dimensión interna de la RSE, tal como se señaló líneas arriba, envuelve el aspecto interno de la empresa, desde los accionistas hasta los trabajadores y sus familias. Actualmente, en este mundo tan competitivo, las personas suelen darle mucha importancia a su trabajo. Una empresa tiene muchas opciones respecto a quién contratar para cubrir un puesto de trabajo. Si yo tuviese una empresa, contrataría a quien pudiera hacerla rendir más. Y naturalmente, se percibe que dichas personas trabajan más que el resto: son aquellas que laboran hasta altas horas de la noche, que extienden los horarios de la empresa, que ponen su trabajo antes de su familia o su pareja.

El caso está en que, dado el competitivo mundo actual, muchas veces estas personas no trabajan más por voluntad propia, sino porque saben que existen otras personas que sí estarán dispuestas a hacerlo. Para ellos, ellas constituyen personas ante las cuales pueden perder su trabajo.

Pero cabe señalar que este no siempre es el caso. No voy a negar que existe gente apasionada por su trabajo, que labora arduamente - incluso noches enteras - porque hace lo que le gusta. Además, podría ser que se trabaje para cumplir con otro grupo de interés: los clientes. Inés Temple señala al respecto lo siguiente: «[...] es fácil idealizar los éxitos profesionales o materiales, creyendo que estos serán suficientes para suplir cualquier carencia afectiva o familiar, por lo menos en el corto plazo» ${ }^{25}$.

TRABAJO GANADOR DEL CONCURSO DE ENSAYOS REALIZADOS ENTRE ALUMNOS DE LA FACULTAD DE DERECHO DE LA PUCP 
Es importante pensar lo que puede suceder en el largo plazo. Por más de que el éxito cortoplacista se presente atractivo, cada uno debe valorar lo que podría estar sacrificando. Acerca de quienes optan por poner su trabajo por sobre todo lo demás, Temple agrega: «[...] es una opción muy válida para quien la escoge siendo muy consciente del precio por pagar, pero he visto a muchos que luego se arrepienten de no haber dedicado más de su vida a cuidar y disfrutar de su familia, sea como sea que esta esté formada $»^{26}$.

Sin embargo, surge un problema cuando la empresa, sabedora de que tiene opciones, exige demasiado a sus trabajadores, pues, si dicha persona no hace el trabajo, alguien más lo hará. Y eso no es todo: es posible que otra persona lo haga incluso a cambio de menos dinero.

¿Cuáles son los intereses afectados en este caso? ¿Y cómo se le presenta la idea de la RSE? Pues pensemos en los actores de reparto alrededor de los protagonistas de esta relación de trabajo. Identifiquemos a los stakeholders afectados: (i) la familia, pues el trabajador pasaría muy poco tiempo con ella; (ii) la empresa, pues un trabajador que trabaja de más a la larga rendirá menos y, además, las personas más capacitadas no querrán trabajar en un lugar que explota a sus trabajadores; (iii) los accionistas, pues la empresa perderá rentabilidad, dado que la gente más capacitada trabajará en lugares donde el ambiente sea más «feliz»; y (iv) los consumidores o usuarios de los servicios o bienes que proporcione la empresa, por los mismos argumentos señalados anteriormente.

$\mathrm{Al}$ respecto, Inés Temple señala que «[...] quienes son verdaderamente consecuentes con sus valores familiares son personas mejor balanceadas espiritual y emocionalmente. $\mathrm{Y}$ al final del día es la persona mejor balanceada la que contribuye mejor y por más tiempo, y cada vez más ${ }^{27}$.

Entonces, una empresa responsable se preocupará de que ser un excelente lugar para trabajar. Al fin y al cabo, son los trabajadores quienes la hacen funcionar $y$, en consecuencia, un trabajador que va contento al trabajo hará felices a todos los stakeholders... y a la larga la más beneficiada será la empresa.

Un primer paso será efectivamente cumplir con lo dispuesto por el Derecho laboral. En este aspecto, pues, el Estado no puede hacer más que limitarse a hacer cumplir las normas laborales. Todo lo demás está en manos de la empresa: cuando esta vea los beneficios de ser el mejor lugar para trabajar, verá que cuenta con las personas más capacitadas y estará más cerca del primer lugar en el mercado. 


\section{III.3.1 Si pagas con maní, obtendrás monos}

La frase del subtítulo corresponde a sir James Goldsmith, un empresario francés cuya mayor parte de su vida pasó en Inglaterra. Estudió en Eton, una de más prestigiosas escuelas británicas, de la cuál se retiró antes de terminar, para formar de manera exitosa una de las más grandes empresas farmacéuticas que ha visto Europa, famosamente conocida por la creación del Alka Seltzer. Pero iqué queremos decir con su frase: «Si pagas con maní, obtendrás monos» (If you pay peanuts, you get monkeys)?

Goldsmith aludía a las empresas que se avocan a conseguir los mejores trabajadores dispuestos a ganar la menor cantidad de dinero. Pagando mal, buscando la mano de obra más barata, no se ven favorecidos ni la empresa, ni los stakeholders. Entiéndase que jugar en favor los stakeholders equivale a jugar en favor de la empresa. Los buenos sueldos son establecidos por el mercado. Si yo quiero que los mejores trabajadores estén en mi empresa, debo ahorrar en todo menos en la comodidad de mis trabajadores.

Es importante tomar en cuenta, desde gerentes hasta practicantes, lo que señala Temple: «[...] la excelencia guarda relación con la experiencia, las habilidades y el espíritu, ese brillo en los ojos de quien muestra sus ganas de hacer las cosas bien, indistintamente de la edad. Esa combinación no cuesta barato, pero pueden estar seguros de que su retorno multiplica lo que se invierte en un profesional con ese perfil ${ }^{28}$.

Muchos empleadores exprimen y respetan poco a los profesionales jóvenes o practicantes —el llamado «derecho de piso»—; sin embargo, invertir en ellos resulta ser, a la larga, más rentable para una empresa. Muchas buscan alguien con experiencia y altamente preparado, lo cual se traduce en una subvaloración del mercado de los recién graduados.

La tarea del Derecho en este aspecto, al igual que en el caso anterior, es mínima. La dimensión interna radica en las relaciones privadas. El Derecho no puede inmiscuirse en estas salvo para hacer valer derechos laborales irrenunciables. El resto de las condiciones serán fijadas por quienes quieran pagar maní y por quienes quieran vestirse de monos.

\section{III.4 Asignación de titularidades y eficiencia}

Otro motivo para viabilizar la intervención del Estado a través de la regulación, tal como lo hemos visto necesario en los ejemplos anteriores sobre la dimensión externa de la RSE, es la presencia de altos costos de transacción que impiden a los agentes darse cuenta de que pueden acercarse a una situación más eficiente. Al fin y al cabo, si la empresa ha tomado la decisión de reinvertir, el Estado puede permitirse promover —indirectamente— la inversión más eficiente.

TRABAJO GANADOR DEL CONCURSO DE ENSAYOS REALIZADOS ENTRE ALUMNOS DE LA FACULTAD DE DERECHO DE LA PUCP 
En los ejemplos anteriores, los principales costos que evitan que se llegue a la situación más eficiente se generan a partir de la falta de información. Si las empresas contaran con información específica acerca de cómo pueden realizar prácticas de RSE, de forma tal que se genere la situación más eficiente, lo harían. Sin embargo, este escenario es costoso. Y si los inversionistas contaran con información acerca de cuáles son las empresas que realizan prácticas de RSE y conocieran las posibilidades de obtener mayores beneficios a través de esta inversión, también lo harían. Sin embargo, los altos costos de transacción derivados de la falta de información representan una barrera alta. Aquí, una norma estatal podría intervenir en favor de la reducción de este costo de transacción, y en consecuencia podría generar una situación más eficiente. A decir de Ronald Coase:

[...] para llevar a cabo transacciones de mercado es necesario descubrir con quién deseamos transar, informar a la gente qué deseamos intercambiar y en qué términos [...] Éstas operaciones son, a menudo, muy costosas; suficientemente costosas para evitar muchas transacciones que se llevarían a cabo en un mundo en el que el sistema de precios funcionase $\sin \operatorname{costos}^{29}$.

En un caso como este, donde los costos de transacción son altos en el sentido de que impiden la situación más eficiente, las normas legales son muy importantes, especialmente si están orientadas a acercarnos a «un mundo sin costos de transacción».

Es relevante detectar cuáles son las razones en las que se basa el Estado para asignar titularidades de derechos $-\mathrm{y}$ por qué luego estas cambian, situación que solo debe ocurrir cuando, descontando los costos de reorganización de titularidades, aún se verifica un mayor valor en la producción-. Guido Calabresi señala que estas razones son tres: (i) eficiencia económica; (ii) preferencias distributivas; y (iii) una cláusula abierta de otras distintas consideraciones de justicia.

Así, el criterio de la eficiencia económica requiere escoger el conjunto de titularidades que «[...] llevaría a una distribución de recursos que no pueda ser perfeccionada, en el sentido [de] que un cambio adicional no mejoraría la condición de aquellos que se beneficiaron por ello», además de que, en cierta medida, «pueda compensar a aquellos que perdieron con la misma medida $»^{30}$.

En el caso de la RSE, es claro que el objetivo de las normas o disposiciones que emita el Estado será informar acerca de los beneficios de la RSE y, en algunos casos, escapar un poco de la característica de voluntariedad ya

29 COASE, Ronald Harry. «El problema del costo social». La empresa, el mercado y la ley. Madrid: Alianza Editorial, 1994, pp. 100 y siguientes.

30 CALABRESI, Guido y Douglas MELAMED. «Reglas de la propiedad, reglas de la responsabilidad e inalienabilidad: un vistazo a la catedral». Themis, № 21, 1992, Lima. Originalmente en Harvard Law Review, vol. 85 . № 6, p. 65, abril de 1972 . 
señalada y premiar a las empresas que la practiquen ${ }^{31}$. La asignación de titularidad pude realizarse mediante una agencia del Estado que canalice la inversión social de la empresa practicante de $\operatorname{RSE}^{32}$ y que colabore con sus obligaciones tributarias (titular del derecho a una menor carga tributaria).

Con respecto a los objetivos distributivos, de acuerdo con Calabresi, estos criterios «[...] implican la distribución de la riqueza misma y la distribución de ciertos bienes específicos» ${ }^{33}$; así, el Estado asignará normas de propiedad, normas de responsabilidad y normas de inalienabilidad a cada individuo. Estos criterios se basan en principios como el de igualdad y el de equidad.

En cuanto a las razones distributivas, un claro ejemplo son los derechos laborale ${ }^{34}$, asignados con el carácter de inalienabilidad. No descartemos, de acuerdo con el análisis realizado líneas arriba, que esta asignación también tenga razones de eficiencia.

Calabresi da la última razón como una cláusula abierta, dadas las amplias definiciones de eficiencia y de distribución equitativa. Podríamos dejar esta opción abierta al libre albedrío de las partes, de su autonomía privada. Este es un criterio subjetivo: ante distintas preferencias, una norma que deje a las partes acordar sus derechos, es decir, que promueva la libertad a través de la ausencia de regulación estatal.

Desde esta perspectiva, suena contradictorio y paradójico que un criterio legitimador de la presencia de la regulación del Estado, que se centre en garantizar la libertad, termine por concluir que esto significaría la ausencia de regulación. Sin embargo, que el Estado garantice que las empresas y los individuos negocien y contraten de manera libre - tal como funciona en la actualidad - lleva consigo ventajas que analizaremos en el siguiente punto.

\section{III.5 No regular la RSE}

Luego del análisis referido a la forma de intervención del Estado a efectos de promover las prácticas de RSE, es necesario analizar si su ausencia en dicho marco sería viable.

Las principales críticas que podrían formularse parten del hecho de que no puede demostrarse que los beneficios de la regulación lleguen a ser superiores a los costos que supongan su imposición. Otra crítica es que

31 No olvidemos que, si bien son características de la RSE la voluntariedad e ir más allá de lo exigido por la ley, su principal objetivo es satisfacer y cumplir las expectativas de todos los grupos de interés con quienes se ve afectada una empresa.

32 El objetivo de esta agencia sería generar la situación más eficiente a partir de la canalización de los recursos de la empresa. Previamente, debe estudiarse si implementarla supera los beneficios de que las propias empresas inviertan de acuerdo a su criterio.

33 CALABRESI. Óp. cit., p. 68.

34 A través de la obligación de participación en las utilidades, de sueldo mínimo, de primer rango de prelación de pago en los procedimientos concursales, etcétera.

TRABAJO GANADOR DEL CON-

CURSO DE ENSA-

YOS REALIZADOS

ENTRE ALUMNOS

DE LA FACULTAD

DE DERECHO DE

LA PUCP 
la RSE puede ser puesta en práctica por el mercado de forma natural. La razón radica justamente en el surgimiento inicial voluntario de este tipo de actividades, sin necesidad de que el Estado las haya exigido o promovido - aunque sí involuntaria e indirectamente en algunos casos, dada su inacción-.

Bajo esta perspectiva, podría afirmarse que, en nuestro país y hasta el momento, la RSE está constituida por acciones y tareas que en muchos casos suplantan acciones y tareas a cargo del Estado - construcción de colegios y carreteras, prevención de contaminación, etcétera-. En consecuencia, el Estado se ve beneficiado como un free-rider. Nótese que su inacción genera una necesidad de acción en las empresas ejecutantes de proyectos, que deben desarrollar obras por sí mismas. Piénsese, por ejemplo, en una compañía que necesita una carretera para transportar sus recursos. Debe construirla por necesidad, y con ello genera beneficios para sí misma, para la localidad donde está ubicada y además para el Estado, que no desembolsó centavo alguno en la construcción. Estas son razones suficientes para afirmar que el mercado perfectamente puede generar prácticas de RSE sin necesidad de ser instado por el Estado.

\section{III.5.1. Asociaciones de empresas practicantes de RSE}

Dowd propone un argumento en contra de la regulación del sistema financiero que puede ayudarnos a demostrar cómo puede ser favorable la ausencia del Estado en el campo de la RSE ${ }^{35}$. Respecto de la regulación bancaria y los altos costos del monitoreo del Estado para este sector, el autor sostiene que las empresas financieras bien pueden establecer «clubes» o asociaciones de cooperación ${ }^{36}$. De acuerdo con él, existen tres razones que sustentan la creación de estos clubes. Las describiremos en función de su aplicación al ámbito de la RSE:

1. La necesidad de reducir costos de transacción y de monitoreo de operaciones, es decir, que todos los miembros se informen sobre cuáles son los agentes que realizan cada tipo de actividad. Ello puede ayudar a que los agentes coordinen y cooperen mutuamente en proyectos similares, o a que establezcan alianzas, dado que en conjunto se podrían realizar proyectos de mayor envergadura y, por lo tanto, más eficientes —como ocurre en una economía de escala-.

35 Kevin Dowd es citado por RUILOBA MORANTE, Augusto. «¿Por qué se regula la actividad bancaria?». lus et Veritas, № 35, p. 284, 2008, Lima. No estoy en contra de la regulación del sistema financiero, pero considero que es un argumento extensivo hacia el ámbito de la RSE y a todas luces válido para sustentar la ausencia de intervención del Estado en él.

36 Cabe señalar que actualmente existe la asociación Perú 2021, la cual está «liderada por empresarios, que desde 1994 viene trabajando para lograr una Visión Nacional compartida de largo plazo, y por la difusión y promoción de la Responsabilidad Social (RS) como metodología de gestión empresarial, para que la empresa se convierta en agente de cambio para alcanzar el Desarrollo Sostenible del Perú». Perú 2021. «¿Qué es Perú 2021?». En <http://www.peru2021.org/index.php?option=com_co ntent\&task=view\&id=5\&ltemid=26>. Fecha de consulta: primero de octubre de 2009. 
2. La posibilidad de tercerizar, de alguna manera, la canalización de recursos destinados a las acciones de RSE. El club sería el ente destinado a desarrollar el proyecto con cargo a las empresas aportadoras de recursos: implementaría los proyectos e involucraría a los miembros que, según crea, se pueden involucrar de manera más eficiente.

3. El club podría servir de incentivo para que las empresas mantengan regularmente actividades de RSE.

Un club, o asociación de todas las empresas dispuestas a realizar prácticas de RSE, puede servir incluso para costear la implementación del índice del mercado de valores que se señaló en el punto anterior. No sería así necesaria la presencia del Estado como promotor de este índice, sino que las mismas empresas lo harían. Los costos no serían significativos y se generarían los beneficios ya señalados. Las mismas empresas harían su propia publicidad y la imagen del club como generador de esta práctica altruista y bien intencionada incentivaría a todos los agentes a formar parte de él.

\section{III.5.2. La competencia}

Otro camino que puede conducir a la situación más eficiente de RSE sin que intervenga el Estado radica en la competencia. El economista Gary Becker, citando a Adam Smith, habla de una «mano invisible» en el mercado: «[...] mientras los individuos están interesados exclusivamente en su propio interés, a través de la competencia siempre se verán llevados — como si existiera una 'mano invisible' — a promover el interés público» ${ }^{37}$.

Becker señala que los efectos beneficiosos de la competencia se registran en áreas donde los competidores no necesariamente están totalmente orientados hacia la obtención de ganancias ${ }^{38}$, sino donde estas se generan indirectamente o bien no se generan. El autor opina que la competencia, a pesar de lo que afirman las críticas, no ocasiona una carrera hacia abajo, sino hacia arriba. Según las críticas, en la competencia de mercados de empresas que venden productos a cambio de dinero, estas disminuyen la calidad de sus productos a efectos de venderlos más barato que sus competidoras, de modo que engañan al consumidor. Por ello, se dice que se observa una carrera hacia abajo, hacia una menor calidad. Sin embargo, esto no siempre ocurre, pues eventualmente los consumidores dan cuenta de la mala calidad del producto y transfieren su preferencia hacia otro.

Existen consumidores que suelen comprar lo primero que ven o lo más barato del mercado; pero también existen consumidores diligentes, que

TRABAJO GANADOR DEL CONCURSO DE ENSAYOS REALIZADOS ENTRE ALUMNOS DE LA FACULTAD DE DERECHO DE LA PUCP 
investigan y averiguan cuál es el mejor producto del mercado y apuntan a ese. Son a ellos a quienes buscan las empresas, pues los demás no se preocupan por investigar y construyen su preferencia con el tiempo, sobre la base del ensayo y el error.

En este sentido, se genera una carrera hacia arriba: las empresas apuntan a satisfacer a los consumidores diligentes que sí dan a conocer sus preferencias, y estos generan externalidades positivas, pues, incentivando a las empresas a proveer productos de calidad, benefician a los consumidores que no son diligentes — quienes se convierten en free-riders-.

Estos beneficios de la competencia se registran en distintos ámbitos en los que obtener mayores ventas deja de ser el objetivo principal, por ejemplo, la educación, la información y la opinión, y hasta el mercado de divisas. En todas las áreas mencionadas se compite por algo. La RSE, dadas las razones señaladas, acarrea un sinnúmero de factores por los cuales las empresas pueden competir.

En su dimensión externa e interna, las empresas compiten por ser favoritas en la comunidad, por tener a los mejores trabajadores del mercado en su planilla y por mejorar su imagen ante inversionistas, en busca de financiamiento, y ante los consumidores, en busca de su preferencia.

Queda claro que, independientemente de un subsidio del Estado - las exoneraciones tributarias que señalamos-, la libre competencia conducirá de manera natural —así como en un principio lo hizo al generar la RSE- a que se mantengan y aumenten los niveles de RSE conforme las empresas crezcan y se tornen más competitivas.

\section{RESUMEN}

He realizado un análisis partiendo de la curiosidad inicial sobre cuál podía ser la relación entre el Derecho y la responsabilidad social empresarial. Los trabajos consultados, la «legislación» y la perspectiva económica alumbraron el camino de esta investigación, y me hicieron cambiar de opinión muchas veces respecto de si la RSE debía o no regularse y en qué forma debía —o no- hacerlo.

Partiendo del concepto inicial, que a su vez nació con los ejemplos de las empresas Coca-Cola y Telefónica del Perú, surgieron las siguientes características de la RSE: es una acción que supera lo exigido por la ley (i) y que, por lo tanto, es voluntaria (ii). Desde acá, y luego de explorar a fondo el concepto, de definir sus alcances, de citar ejemplos de acciones de RSE, y de clasificar sus objetivos con referencia a los efectos en el interior de la empresa y fuera de esta (dimensiones interna y externa), se dilucidaron las principales razones que dan origen a la RSE.

La «legislación», bajo la forma de lineamientos creados por la Comisión Europea, buscaba generar un debate en torno a cómo fomentar la RSE 
en las empresas. El Libro Verde establece ejemplos de acciones de RSE y expone ideas acerca de cómo puede manifestarse la práctica de la RSE. Desde mi punto de vista, el Libro Verde ya asume que las empresas conocen los beneficios que obtendrán con su práctica.

A partir de esta información, me atreví a ensayar, mediante el planteamiento de supuestos, por qué en ciertos casos una empresa debe optar por una acción socialmente responsable y obtener los mismos beneficios económicos que obtendría si no lo fuese, pero con el plus de generar un beneficio a la sociedad. Partí de un ejemplo sobre cómo es que se «crea» Derecho, al señalar que, si nuestro Congreso percibe «síntomas» indeseados en la sociedad, puede aplicar un «tratamiento» que corrija la situación. En este caso, se busca generar un síntoma (la RSE), por lo que la creación de un tratamiento puede ser deseable.

Sugerí que el Estado otorgue beneficios tributarios al impuesto a la renta aplicado a las utilidades de la empresa destinadas a la inversión social. Tomando en cuenta que tanto la entrega de dividendos como la reinversión de utilidades están gravadas con el impuesto a la renta de la forma en que el Estado quiere dirigir el sistema - tal como lo señalé en el punto III.2.1-, planteé que también puede dirigirlo a generar más RSE. Otra forma de intervención podría ser publicitar e informar a los stakeholders acerca de estas acciones. La vía puede ser una agencia de RSE que canalice recursos y comunique a los agentes para que se realicen las acciones más eficientes - y que en consecuencia reduzca costos de transacción-, y que promueva un índice en el mercado de valores que agrupe a las empresas que practican RSE.

Después analicé la dimensión interna de las empresas, el tratamiento a los trabajadores y a los accionistas. En este aspecto, dimos cuenta de que una empresa que realice buenas prácticas de gobierno corporativo, que respete los derechos de los trabajadores y que los valore de la mejor manera sería la más eficiente. No se debe olvidar que toda gran empresa tiene detrás también un grupo de personas que le otorgó dicha posición. En este aspecto, al tratarse de relaciones privadas, el Estado no tiene cabida. No existe argumento alguno en favor de una intervención adicional del Estado en este aspecto, salvo asegurar la eficacia de las normas ya existentes. Toda valorización adicional que haga la empresa en referencia al trato a sus accionistas, sus trabajadores y su mecanismo político interno es subjetiva.

Luego de los ejemplos analizados, expliqué las razones económicas de la intervención del Estado en la generación de normas mediante la atribución de titularidades a los agentes. Razones de eficiencia, equidad y otras consideraciones de justicia fueron ejemplificadas.

Por último, traté el tema de la «no regulación» de la RSE. No olvidemos que un marco ausente de regulación promovió el surgimiento de la RSE en un inicio. Analizando este escenario, descubrimos que una de las 
tareas propuestas al Estado, como la creación de una agencia de RSE, podía ser suplantada por una asociación o club fundado por las propias empresas. Una asociación sería más eficiente que una nueva entidad estatal, pues la manejarían las mismas empresas, las cuales se apoyarían mutuamente para incluso crear programas de RSE de mayor envergadura. Esta asociación podría impulsar la creación del mencionado índice en el mercado de valores al señalar y agrupar a las empresas practicantes de RSE, lo cual generaría que todas las demás aspirasen a pertenecer al club y, por tanto, a figurar en el índice.

Hubo otro argumento en favor de no regular la RSE: mediante la competencia, se puede lograr desarrollarla. Sin necesidad de subsidios a actividades particulares, las empresas inician una carrera hacia arriba y apuntan a satisfacer a los stakeholders, dadas las razones y los beneficios ya señalados. La única tarea del Estado en este aspecto consistiría en eliminar barreras burocráticas que permitan implantar este tipo de proyectos sin tener que preocuparse por fiscalizarlos y delinearlos, ni por intervenir en la dimensión interna de la RSE.

En conclusión, existen distintos caminos para fomentar la RSE. La viabilidad de cada uno debe ser evaluada tomando en cuenta de qué manera se logrará una situación más eficiente. No soy partidario de imponer regulaciones, dado que los costos de imponerla deben ser confrontados con los beneficios que pueda generar antes de llegar a una conclusión. Sin embargo, sí considero necesaria una menor carga tributaria para el porcentaje de impuesto a la renta aplicado a las utilidades destinadas a la inversión social, que debería ser confrontada con la carga establecida tanto para la distribución de dividendos como para la reinversión de utilidades. La inversión social favorece el interés público; ante ello, es tarea del Estado incentivar acciones que favorezcan a todos, principalmente al propio Estado. 